\title{
Perceptions of Saskatchewan Community Pharmacists Regarding a Prior-Authorization Program
}

\author{
Jason Perepelkin, MSc, and Roy Thomas Dobson, PhD
}

\begin{abstract}
BACKGROUND: In 1999, Saskatchewan Health authorized pharmacists to initiate exception drug status (EDS) requests, also known as prior authorization (PA). Before 1999, only those licensed to prescribe medications were authorized to initiate EDS requests. A pharmacist who submits an EDS request must obtain a patient diagnosis from the physician or agent of the physician; a diagnosis presented by the patient is insufficient.
\end{abstract}

OBJECTIVE: To obtain pharmacists' opinions about the benefits of the PA program of the Saskatchewan Drug Plan and to identify factors associated with pharmacist-initiated EDS requests.

METHODS: A census survey of community pharmacy managers was conducted via a self-administered postal questionnaire in the province of Saskatchewan, Canada, in the fall of 2004. The survey questionnaire was addressed to pharmacy managers, some of whom may have delegated the response to a staff pharmacist. Pharmacy managers or their delegates were asked to respond on behalf of all pharmacists in their pharmacies.

RESULTS: A response rate of $82.6 \%$ was achieved (275/333). A majority of respondents agreed that the province's PA program (EDS) benefited patients $(87.3 \%)$ and the Saskatchewan Drug Plan (82.5\%), whereas only $33.4 \%$ of respondents agreed that the EDS program benefited pharmacists. Pharmacists' ability to obtain the requisite information $(87.6 \%)$ and to contact the prescribing physician $(87.3 \%)$, as well as patient-centered concerns such as the patient's ability to pay for the prescription (85.1\%), were the most important factors. The time required by the pharmacist to initiate the request was not important relative to other factors. Community pharmacies reported receipt of an average of 36.4 prescriptions for restricted and nonformulary drugs per week, of which 22 were submitted for PA coverage, 17 by the pharmacy and 5 by the pharmacy at the request of the physician.

CONCLUSIONS: The results of this study indicate that community pharmacists in Saskatchewan acknowledge that the EDS process is beneficial for their patients. However, pharmacists are burdened by an administrative process in which necessary information, particularly the patient diagnosis, is not readily available.

KEYWORDS: Pharmacist, Policy, Prior authorization, Step therapy, Drug plan J Manag Care Pharm. 2007:13(7):589-97

Copyright@ 2007, Academy of Managed Care Pharmacy. All rights reserved.

\section{What is already known about this subject}

- Prior-approval or prior-authorization (PA) programs reduce direct drug cost by imposing criteria for coverage such as prior use of first-line therapy (i.e., step therapy) or a patient diagnosis with a higher probability of a favorable response to the drug.

- As prescription drug use increases, drug and managed care plan administrators are developing and implementing costcontainment mechanisms to encourage the use of lower-cost drugs while promoting cost-effective use of more expensive and generally newer drug therapies.

\section{What this study adds}

- This is the first study of the opinions of pharmacists with regard to the administrative procedures involved in a PA program.

- Pharmacy managers and pharmacists are not opposed to PA programs but are dissatisfied with the administrative burden of the requirement to obtain the patient diagnosis from the physician.

$\mathrm{M}$ edicare in Canada is a federal program that has evolved over nearly 40 years to provide Canadians access to medically necessary physician and hospital services, including drugs administered in hospitals. However, each provincial and territorial government independently developed and continues to develop programs to provide drug coverage for some or all of its residents in the community or in nonhospital facilities. The federal government has also developed and continues to develop drug programs for select groups, including veterans and First Nations and Inuit peoples. However, more than half of all prescriptions are paid through private insurance or directly by individuals or patients. ${ }^{1,2}$

In 2005, Canada had 7,778 community pharmacies comprising chain and banner pharmacies (58.6\%), independent pharmacies (21.4\%), and pharmacies in food and mass merchandisers (20.0\%). ${ }^{3}$ In 2005 in Saskatchewan, public funds paid for 48\% of the \$554 per capita spent on prescription drugs, whereas Canada as a whole spent $\$ 640$ per capita on prescription drugs, with $46 \%$ of the expenditure paid for with public funds. ${ }^{4}$ The average retail price for a prescription in 2005 was \$45.66, which included dispensing and professional fees. ${ }^{3}$ As in other countries, the final cost to the patient varied considerably depending on the markup and dispensing fee charged. 
Over the years, increasing reliance on drug therapy and a tendency to abandon older drug therapies for newer, more expensive agents have caused drug utilization rates and expenditures for prescription drugs to grow substantially.1,5,6 Drug plans have attempted to control these rising costs in a variety of ways, including limiting coverage to certain cohorts of the population (i.e., low-income families), increasing copayments, or introducing deductibles. The result has been an ongoing shifting of costs to patients and private insurers. 7,8

In 1973, the Saskatchewan provincial government implemented a comprehensive drug plan via Saskatchewan Health's Drug Plan and Extended Benefits (Drug Plan) Branch. All costs, with the exception of a small copayment, were publicly funded.7,9 Today, Saskatchewan residents are still covered by the provincial drug plan, but most beneficiaries must meet an annual, incomebased deductible (3.4\% of household income) before receiving any financial support from the government. 9 Since July 2007, seniors (all Saskatchewan residents aged 65 years and older) pay no more than Can $\$ 15$ per prescription (1-month supply) for drugs listed on the province's formulary. 10

Utilization trends in Saskatchewan provide an interesting picture of drug expenditures in the province. In 1995-1996, 633,333 active beneficiaries in Saskatchewan received 5,798,090 prescriptions for a total prescription cost of Can \$157,194,207 (Can \$248 per beneficiary), and the Drug Plan paid Can \$59,492,033 (37.8\%) of the total cost. ${ }^{9}$ Ten years later, in 2005-2006, the number of active beneficiaries had increased by only $0.8 \%$ to 638,637 , while the number of prescriptions increased $62 \%$ to $9,364,871$ and total prescription costs increased by $239 \%$ to Can $\$ 375,304,926$ (Can $\$ 588$ per beneficiary); the Saskatchewan Drug Plan paid Can $\$ 181,288,493$ (48.3\%) of the total prescription cost, an increase of $305 \% .{ }^{9}$

Therefore, while the number of active beneficiaries remained virtually unchanged, the number of prescriptions per active beneficiary, average cost per prescription, and per prescription proportion paid by the Saskatchewan Drug Plan increased dramatically. Managed care interventions that have been implemented, such as prior authorization (PA) in the late 1970s and therapeutic maximum allowable cost, which began with proton pump inhibitors in July 2004, are attempts by the Saskatchewan Drug Plan to control escalating costs and thereby ensure its long-term viability.

Even with restrictive policies and cost shifting, drug utilization rates continue to rise and, with them, the cost of providing drug coverage. ${ }^{11}$ Both public and private drug plans have expanded various management strategies such as PA in an attempt to stem rising drug expenditures while maintaining access to effective drug therapies. PA limits the use of selected drugs by requiring advance approval for reimbursement of certain drugs when less costly alternatives are available. ${ }^{12}$ However, some aspects of these strategies can become sources of contention between payers, patients, and health care providers because they may be perceived as limiting access to needed drugs by requiring administrative approval for coverage.
Additional administrative tasks are associated with these programs that health care professionals are expected to assume.13

In Saskatchewan, PA is known as the Exception Drug Status (EDS) program. ${ }^{14}$ For the patient to receive provincial government coverage for restricted formulary drugs, EDS approval must first be obtained - a process that must be initiated by an authorized health care professional (physician, dentist, optometrist, nurse practitioner, or pharmacist). Some private drug plans have the same or similar requirements for drugs in the Saskatchewan EDS program. A few examples of EDS program drugs and coverage criteria include azithromycin permitted for patients intolerant to erythromycin and/or other antibiotics, insulin lispro permitted for treatment of patients using insulin pumps or difficult-to-control diabetes, and pioglitazone hydrochloride $(\mathrm{HCl})$ or rosiglitazone maleate permitted for treatment of patients who previously received prescriptions for metformin or sulfonylureas and are not adequately controlled on or are intolerant to metformin or sulfonylureas. ${ }^{15}$

When submitting an EDS request, the authorized health care professional can phone, mail, or fax the request to Saskatchewan Health; however, only the patient and prescribing physician receive confirmation letters. The pharmacist is notified when he or she accesses the patient profile via the Drug Plan's database. Information required to submit an EDS request includes the (1) patient name, (2) patient health services number, (3) diagnosis relevant to use of drug, and (4) prescriber name and phone number. ${ }^{15}$ The information required to submit an EDS request for a nonapproved drug includes (1) the disease or problem treated, (2) the list of previous therapies and responses, (3) other non-EDS therapies tried and why they are not appropriate for the patient, (4) clinical evidence to support the therapy being requested, and (5) outcomes to assess effectiveness of the requested therapy. ${ }^{15}$ (Figure for EDS request form. ${ }^{16)}$

In July 2006, the Drug Plan implemented online adjudication for 2 drugs (pioglitazone $\mathrm{HCl}$ and rosiglitazone maleate) through an electronic step-therapy program. EDS claims for these 2 drugs can be submitted and adjudicated directly through the online claims transaction system. ${ }^{15}$ For these 2 drugs, the online transaction processing system checks the patient's drug profile and if the first-line drugs (metformin or sulfonylureas) appear in the system, the coverage and approval letter is automatically generated for the patient..$^{15}$

Health care professionals as a whole are not compensated by the Saskatchewan Drug Plan for EDS requests. However, the Medical Services Branch (not the Saskatchewan Drug Plan and Extended Benefits Branch that administers the EDS program), compensates physicians Can $\$ 4$ for information requests from health care professionals, including pharmacists, for a diagnosis from the physician to submit an EDS request. (written communication, G. Bradley, January 2005). Therefore, if the physician writes on the prescription "apply for EDS" but does not provide the required diagnosis on the written prescription, when the pharmacist contacts the physician to obtain the patient's diagnosis, the physician may claim a Can $\$ 4$ fee for that information request. 
Saskatchewan

Health
Drug Plan \& Extended Benefits Branch

3475 Albert Street

Regina SK SAS 6X6

306-787-3420 Phone

306-798-1089 Fax

\section{EXECEPTION DRUG STATUS REQUEST FORM}

DATE:

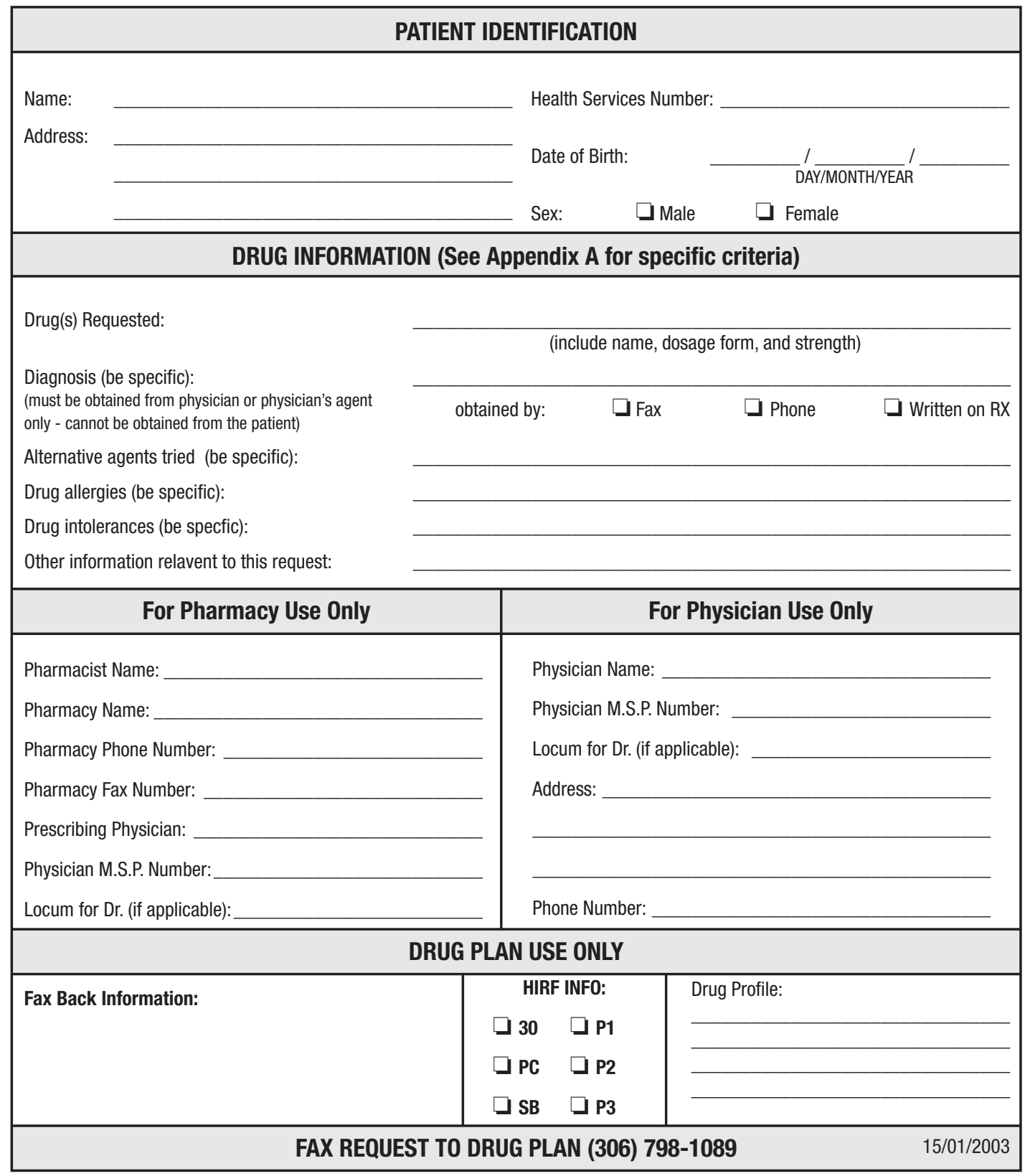


Before 1999, only those practitioners licensed to prescribe in the province were able to initiate EDS requests. In 1999, Saskatchewan Health expanded the program to allow licensed pharmacists to apply for EDS on behalf of their patients. Allowing pharmacists to initiate these requests was seen as a way to improve access to prescription medication and assist patients in securing all available sources of funding for their prescription medications. ${ }^{14}$ However, the EDS program requires the pharmacist to obtain the patient's diagnosis from the physician or physician's agent in order to submit an EDS request. ${ }^{15}$

Since 1999, when licensed pharmacists in Saskatchewan were allowed to initiate EDS requests, research has not been conducted on how the policy affects community pharmacy practice. As noted in previous studies on PA or step-therapy programs, ${ }_{17-20}$ often the drug costs and savings are evaluated while the perspective of the providers (e.g., pharmacists) are not addressed. This paper reports on the experiences and opinions of community pharmacy managers, or their delegates, and their pharmacies with regard to Saskatchewan Health's EDS program and its effect on community pharmacy. Ethics approval was applied for and received from the University of Saskatchewan's Behavioural Research Ethics Board before this survey was conducted.

\section{Methods}

\section{Study Sample and Design}

A census survey of community pharmacy managers in Saskatchewan was conducted in the fall of 2004. Pharmacy managers were chosen over individual pharmacists to reduce the potential of having 2 or more pharmacists' perspectives represented from the same pharmacy. In September 2004, we received an up-to-date list of all 346 community pharmacies in the province from the Saskatchewan College of Pharmacists, the regulatory body for pharmacists in Saskatchewan. In identifying distinct community practices, we reduced the number to 333 as a result of pharmacy closure (1) and of pharmacies operating as satellites in remote communities that did not have a pharmacy manager and/or pharmacist specifically for the satellite location (12).

Following the Tailored Design Method for the conduct of surveys, we sent a prior notice letter in October 2004 to community pharmacy managers who were licensed pharmacists. ${ }^{21}$ In the letter, prospective survey respondents were asked to complete the questionnaire when it arrived or to designate a member of their staff whom they thought was most qualified to answer. This presurvey letter was followed 1 week later by the questionnaire, which included a cover letter and prestamped return envelope. A reminder postcard to nonresponders was sent 2 weeks later. A final mailing was sent 2 weeks after the reminder postcard to nonrespondents and included another copy of the questionnaire, a cover letter, and a prestamped return envelope. The study collection period closed 4 weeks after the final mailing.

Once the study period concluded, we performed a nonrespondent survey. A one-time questionnaire and cover letter, along with a prestamped return envelope, were sent to nonrespondents in an attempt to estimate potential biases in the sample.

\section{Survey Instrument}

Drawing on a review of the relevant literature, 6,22-44 we constructed the questionnaire to address a series of topics relating to PA and the EDS program in Saskatchewan. These topic areas included potential stakeholder benefits from a PA program, the volume of EDS requests received by the pharmacy, factors influencing the decision to initiate a request, and the appropriateness of procedures used to submit a request. Information was also gathered with regard to the area, location, and type of pharmacy; the number of pharmacists and pharmacy technicians in the respondent's pharmacy; the proximity of the prescribing physicians; prescription volume; and hours the dispensary was open. Demographics were also collected on respondents' gender, age, position, and years in their current position.

After the questionnaire was developed, content and format were evaluated using a pretest involving 5 community pharmacy managers. In the pretest, managers were asked to provide feedback on the design of the questionnaire, its relevance, and the flow of individual questions and between sections. Comments were also obtained from Saskatchewan Drug Plan representatives and an expert in questionnaire design from the Department of Management and Marketing, College of Commerce, University of Saskatchewan.

The final instrument contained 5 pages of questions with an average of 8 questions on each page (a copy of the instrument is available from the corresponding author). Items were measured primarily with 5-point and 7-point Likert-type scales. Respondents were also asked to complete a demographics page, and space was provided for additional comments, which are reported elsewhere. 46

\section{Data Analysis}

Descriptive statistics were calculated for all items. Comparative analysis was carried out using the Mann-Whitney $U$ test and Kruskal-Wallis One-Way Analysis of Variance. Nonparametric tests were selected over parametric tests because of the primarily ordinal nature of the data. For post hoc analysis, the Bonferroni test was used to identify statistically significant differences between respondents when factors were compared. All statistical analyses were conducted using SPSS 13.0 for Windows (Chicago, IL).

\section{Results}

\section{Study Population}

A total of 279 questionnaires were returned. After data collection concluded, 4 additional questionnaires were received but were not included in the analysis. Of the eligible questionnaires received, 275 were properly completed, for a final response rate of $82.6 \%$ (275/333). Of the 50 nonrespondent questionnaires that were mailed after the study period, 15 were returned 
(30\%). There were no statistically significant differences between respondents of the original survey and respondents of the nonrespondent survey on any common measures, including gender, respondents' position, proximity to prescriber, community size, average number of prescriptions filled per week, and hours the pharmacy was open (data not presented).

Of the 273 respondents reporting their gender, nearly two thirds were male (64.2\%). Almost half (49.1\%) identified themselves as the manager, and more than one third of respondents identified themselves as the owner (36.4\%). The reported average prescription volume per week (745, Table 1) is lower than the national average of 833.5 The average number of pharmacists (2.8) and pharmacy technicians (2.4) per location were also below the national average of 3.5 and 4.3 , respectively. ${ }^{5}$

An average of 36 restricted/nonformulary prescriptions were received per week which represented $5 \%$ of the reported prescription volume (Table 1). Compared with 1999, when pharmacies did not submit any EDS requests, we found that respondents reported that their pharmacies submitted 79\% of all requests, with $29 \%$ of these EDS requests submitted by the pharmacy at the request of the prescribing physician. Therefore, community pharmacies submit an average of about 17 EDS requests per week out of the 59\% of 22 of the restricted and nonformulary prescriptions received by the pharmacy and submitted by either the pharmacy or physician. Circumstances such as the patient not meeting the

\begin{tabular}{|c|c|}
\hline $\begin{aligned} \text { TABLE 1) } & \text { Pharmacy Characteristics } \\
& \text { Exception Drug Status (ED }\end{aligned}$ & Volumes \\
\hline Pharmacy Characteristics - Saskatchewan $\left(\mathrm{n}=275^{*}\right)$ & Mean $[S D]$ \\
\hline Number of pharmacists & $2.8[1.6]$ \\
\hline Full-time equivalents & $2.4[1.4]$ \\
\hline Number of pharmacy technicians & $1.4[1.7]$ \\
\hline Full-time equivalents & $1.0[1.3]$ \\
\hline Prescriptions per week & $745[504]$ \\
\hline Pharmacy hours per week & $62.0[22.6]$ \\
\hline Exception Drug Status Volume Per Week & \\
\hline $\begin{array}{l}\text { Number of restricted/non-formulary prescriptions } \\
\text { received - mean [SD] }\end{array}$ & $36.4[48.4]$ \\
\hline Number (\%) submitted for coverage $\dagger$ & $22(59.1 \%)$ \\
\hline Number (\%) initiated by the pharmacy & $17(78.8 \%)$ \\
\hline Number (\%) initiated by pharmacy at physician's request & $5(29.4 \%)$ \\
\hline $\begin{array}{l}\text { *48 (17.5\%) of these } 275 \text { pharmacies were located in the same } \\
\text { scribers of EDS drugs. } \\
+ \text { Circumstances such as the patient not meeting the EDS exce } \\
\text { not having tried previous drug therapies required for approv } \\
\text { tests done such as culture and sensitivity for some antibiotics } \\
\text { some requests unnecessary. }\end{array}$ & $\begin{array}{l}\text { lding with pre- } \\
\text { criteria (e.g., } \\
\text { not having the } \\
\text { kes submission of }\end{array}$ \\
\hline
\end{tabular}

EDS exception criteria (e.g., not having tried previous drug therapies required for approval or not having the tests done [such as culture and sensitivity for some antibiotics]) makes submission of some requests unnecessary.

\section{Stakeholders and the EDS Program}

A majority of respondents (63\%) agreed or strongly agreed that the EDS program benefited patients by expanding the number of prescription medications covered by the provincial drug plan (Table 2). A majority (64\%) also agreed or strongly agreed that the provincial drug plan benefited from the EDS program by allowing costly medications to be available in a more controlled manner.

Fewer respondents agreed or strongly agreed that the EDS program benefited the health care system (39\%) by promoting more appropriate utilization of drugs, while $37 \%$ of community pharmacy managers agreed or strongly agreed that the EDS program benefited physicians by providing them with more drug therapy choices for their patients. Only 15\% of respondents agreed or strongly agreed that the EDS program benefited pharmacists by providing them with an opportunity to be more actively involved in securing the most appropriate drug therapy for their patients.

\section{Factors Associated With a Pharmacist-Initiated EDS Request}

In assessing the importance of factors that might influence whether a pharmacist initiated an EDS request on behalf of the patient, $74 \%$ of respondents indicated the ability of the patient to pay for the prescription was an important or very important factor (Table 3). Other factors seen as important or very important in initiating an EDS request included the ability to obtain all the information needed to make the request $(77 \%)$ and the pharmacist's ability to contact the prescribing physician (70\%). Respondents who were in the same location (co-located in the same building) as the prescribing physician were less likely to consider proximity as a factor compared with those who were removed geographically $\left(\chi^{2}=18.41 ; P<0.01\right.$, data not shown in tables). The time required to submit an EDS request was seen as the least important factor, with only 39\% indicating this factor as important or very important.

\section{Experience With EDS Requests}

Seventy-nine percent of respondents agreed or strongly agreed that pharmacists in their pharmacy believe that initiating an EDS request is an important service for their patients, and $75 \%$ agreed or strongly agreed that they had adequate information on the administrative nature of the EDS program (Table 4).

With regard to the 1999 policy change allowing pharmacists to initiate EDS requests, $71 \%$ agreed or strongly agreed that the change in policy had been beneficial to patient care. However, most (96\%) agreed that the change had significantly increased 
the administrative workload of pharmacists, but pharmacies that filled 0 to 250 prescriptions per week (15.9\%) were less likely to agree with this statement than were those filling more than 500 (58.0\%) prescriptions per week $\left(\chi^{2}=12.87 ; P<0.01\right.$, data not shown in tables).

\section{Discussion}

As prescription drug use and expenditures continue to increase, ${ }^{11}$ various interventions such as PA are implemented to manage the use of pharmaceuticals — targeting drugs for which there are less costly alternatives available.12 The principal stakeholders in PA programs are patients, pharmacists, physicians, drug plans, and administrators. $28,34,36,39,41$ Traditionally, physicians have been the health care professionals that apply for PA coverage for a patient, but some drug plans such as the Saskatchewan Drug Plan have authorized pharmacists to also initiate PA requests.

Other researchers have established the financial benefits of PA or step-therapy programs by identifying a reduction in direct drug costs. ${ }^{18-20}$ Through the examination of one aspect of the humanistic-service outcomes, the present study expands our understanding of PA programs. Specifically, we examined some of the factors associated with the uptake of a policy designed to allow pharmacists to apply for PA on behalf of their patients and the perceptions of community pharmacists associated with this policy.

While we did not measure the proportion of pharmacy staff time required for EDS submissions, the administrative burden is not small since preparing and submitting EDS requests requires more time than simply filling the prescription. Furthermore, pharmacists are not compensated financially for the service. It is not surprising that most respondents indicated that the current EDS policy was beneficial to patients and precribers but viewed the policy as an additional burden for pharmacists.

Given the additional workload demands that the EDS program places on pharmacists, it was not unexpected that the respondents believed that pharmacists benefited the least from the EDS program. However, it was somewhat surprising that pharmacists reported that the time required to provide the service was the least important factor when deciding to initiate an EDS request. Factors such as the ability to obtain the required information and the ability to contact the prescriber were of greater concern. This suggests a need to improve communication and the role definition for both the pharmacist and the physician. Effective communication and collaboration between physicians and pharmacists will likely improve humanistic-service outcomes for patients, including reduction in the time delays in obtaining medications. 18

Respondents in the same location as prescribing physicians were less likely to be concerned with their ability to contact the physician. Co-locations and greater opportunity for face-to-face

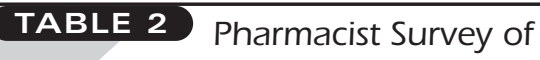 EDS Value-Number (\%)}

\begin{tabular}{|c|c|c|c|c|c|}
\hline $\begin{array}{l}\text { The EDS } \\
\text { program } \\
\text { benefits ... }\end{array}$ & $\begin{array}{c}\text { Agree or } \\
\text { Strongly } \\
\text { Agree }\end{array}$ & $\begin{array}{c}\text { Somewhat } \\
\text { Agree }\end{array}$ & Neutral & $\begin{array}{c}\text { Somewhat } \\
\text { Disagree }\end{array}$ & $\begin{array}{c}\text { Disagree } \\
\text { or } \\
\text { Strongly } \\
\text { Disagree }\end{array}$ \\
\hline $\begin{array}{l}\text { patients by } \\
\text { making their } \\
\text { prescription } \\
\text { drug more } \\
\text { affordable. }\end{array}$ & $\begin{array}{c}132 \\
(48.1)\end{array}$ & $\begin{array}{c}87 \\
(31.8)\end{array}$ & $\begin{array}{c}12 \\
(4.4)\end{array}$ & $\begin{array}{c}19 \\
(6.9)\end{array}$ & $\begin{array}{c}24 \\
(8.8)\end{array}$ \\
\hline $\begin{array}{l}\text { patients by } \\
\text { expanding the } \\
\text { number of } \\
\text { drugs covered. }\end{array}$ & $\begin{array}{c}173 \\
(63.2)\end{array}$ & $\begin{array}{c}67 \\
(24.5)\end{array}$ & $\begin{array}{c}8 \\
(2.9)\end{array}$ & $\begin{array}{c}11 \\
(4.0)\end{array}$ & $\begin{array}{c}15 \\
(5.5)\end{array}$ \\
\hline $\begin{array}{l}\text { physicians } \\
\text { by providing } \\
\text { more drug } \\
\text { therapy } \\
\text { choices for } \\
\text { their patients. }\end{array}$ & $\begin{array}{c}101 \\
(37.0)\end{array}$ & $\begin{array}{c}80 \\
(29.1)\end{array}$ & $\begin{array}{c}22 \\
(8.1)\end{array}$ & $\begin{array}{c}30 \\
(10.9)\end{array}$ & $\begin{array}{c}40 \\
(14.3)\end{array}$ \\
\hline $\begin{array}{l}\text { pharmacists } \\
\text { by being } \\
\text { more actively } \\
\text { involved } \\
\text { in securing } \\
\text { the most } \\
\text { appropriate } \\
\text { drug therapy. }\end{array}$ & $\begin{array}{c}41 \\
(15.0)\end{array}$ & $\begin{array}{c}51 \\
(18.5)\end{array}$ & $\begin{array}{c}36 \\
(13.1)\end{array}$ & $\begin{array}{c}46 \\
(16.8)\end{array}$ & $\begin{array}{c}100 \\
(36.5)\end{array}$ \\
\hline $\begin{array}{l}\text { drug plan by } \\
\text { allowing costly } \\
\text { drug therapies } \\
\text { to be available } \\
\text { in a more } \\
\text { controlled } \\
\text { fashion. }\end{array}$ & $\begin{array}{c}176 \\
(64.2)\end{array}$ & $\begin{array}{c}51 \\
(18.5)\end{array}$ & $\begin{array}{c}19 \\
(6.9)\end{array}$ & $\begin{array}{c}12 \\
(4.4)\end{array}$ & $\begin{array}{c}16 \\
(5.8)\end{array}$ \\
\hline $\begin{array}{l}\text { health care } \\
\text { system by } \\
\text { promoting } \\
\text { appropriate } \\
\text { drug use. }\end{array}$ & $\begin{array}{c}106 \\
(38.7)\end{array}$ & $\begin{array}{c}84 \\
(30.7)\end{array}$ & $\begin{array}{c}19 \\
(6.9)\end{array}$ & $\begin{array}{c}34 \\
(12.4)\end{array}$ & $\begin{array}{c}31 \\
(11.3)\end{array}$ \\
\hline
\end{tabular}

EDS $=$ exception drug status.

interaction allows the pharmacist(s) to establish good working relationships with prescribers. Good working relationships, in turn, would be expected to support greater accessibility when initiating an EDS request.

The ability of the patient to pay was also a key factor in pharmacist decisions to submit requests for EDS coverage. If a patient is unable to pay the cost share for the medication, even if approved via EDS, it is not productive for the pharmacist to apply for EDS coverage. 
Perceptions of Saskatchewan Community Pharmacists Regarding a Prior-Authorization Program

TABLE 3 Factors Associated With the Pharmacy Initiating an EDS

\begin{tabular}{|c|c|c|c|c|c|}
\hline $\begin{array}{l}\text { Factors Determining Whether the } \\
\text { Pharmacy Will Initiate an EDS Request }\end{array}$ & $\begin{array}{l}\text { Very Important/ } \\
\text { Important } \\
\text { n (\%) }\end{array}$ & $\begin{array}{l}\text { Somewhat } \\
\text { Important } \\
\text { n (\%) }\end{array}$ & $\begin{array}{l}\text { Neutral } \\
\text { n (\%) }\end{array}$ & $\begin{array}{l}\text { Somewhat } \\
\text { Unimportant } \\
\text { n (\%) }\end{array}$ & $\begin{array}{l}\text { Very Unimportant/ } \\
\text { Unimportant } \\
\text { n (\%) }\end{array}$ \\
\hline \multicolumn{6}{|l|}{ Processing } \\
\hline $\begin{array}{l}\text { Ability to obtain all the } \\
\text { necessary information }\end{array}$ & $211(76.7)$ & $30(10.9)$ & $10(3.6)$ & $6(2.2)$ & $18(6.5)$ \\
\hline $\begin{array}{l}\text { Ability to track the status } \\
\text { of the EDS request }\end{array}$ & $141(51.3)$ & $54(19.6)$ & $38(13.8)$ & $6(2.2)$ & $36(13.1)$ \\
\hline $\begin{array}{l}\text { Ability to contact the } \\
\text { prescribing physician }\end{array}$ & $193(70.2)$ & $47(17.1)$ & $14(5.1)$ & $2(0.7)$ & $19(6.9)$ \\
\hline Time needed to submit an EDS request & $107(38.9)$ & $43(15.6)$ & $25(9.1)$ & $21(7.6)$ & $79(28.7)$ \\
\hline $\begin{array}{l}\text { Familiarity with the EDS } \\
\text { administrative processes }\end{array}$ & $123(44.7)$ & $37(13.5)$ & $54(19.7)$ & $10(3.6)$ & $50(18.2)$ \\
\hline \multicolumn{6}{|l|}{ Patient Costs } \\
\hline $\begin{array}{l}\text { Patient will eventually exceed } \\
\text { the deductible }\end{array}$ & $163(59.3)$ & $60(21.8)$ & $21(7.6)$ & $12(4.4)$ & $19(6.9)$ \\
\hline $\begin{array}{l}\text { Patient has exceeded the } \\
\text { drug plan deductible }\end{array}$ & $181(65.8)$ & $49(17.8)$ & $17(6.2)$ & $9(3.3)$ & $19(6.9)$ \\
\hline $\begin{array}{l}\text { Ability of the patient to pay } \\
\text { for the prescription }\end{array}$ & $202(73.5)$ & $32(11.6)$ & $11(4.0)$ & $12(4.4)$ & $18(6.5)$ \\
\hline
\end{tabular}

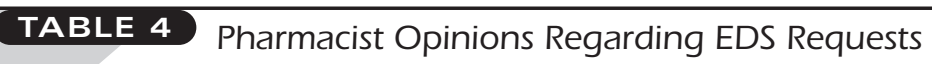

\begin{tabular}{|c|c|c|c|c|c|}
\hline & $\begin{array}{l}\text { Strongly Agree/ } \\
\text { Agree } \\
\text { n (\%) }\end{array}$ & $\begin{array}{c}\text { Somewhat } \\
\text { Agree } \\
\text { n (\%) }\end{array}$ & $\begin{array}{c}\text { Neutral } \\
\mathrm{n}(\%)\end{array}$ & $\begin{array}{c}\text { Somewhat } \\
\text { Disagree } \\
\text { n (\%) }\end{array}$ & $\begin{array}{c}\text { Strongly Disagree } \\
\text { Disagree } \\
\text { n (\%) }\end{array}$ \\
\hline $\begin{array}{l}\text { Pharmacists have adequate } \\
\text { information about program }\end{array}$ & $207(75.3)$ & $44(16.1)$ & $13(4.7)$ & $7(2.5)$ & $3(1.1)$ \\
\hline $\begin{array}{l}\text { Initiating EDS is an important } \\
\text { service to patients }\end{array}$ & $218(79.3)$ & $35(12.7)$ & $12(4.4)$ & $4(1.5)$ & $6(2.2)$ \\
\hline $\begin{array}{l}\text { Policy change is beneficial to } \\
\text { patient health care }\end{array}$ & $195(70.9)$ & $43(15.6)$ & $19(6.9)$ & $6(2.2)$ & $12(4.4)$ \\
\hline $\begin{array}{l}\text { Program contributes } \\
\text { significantly to workload }\end{array}$ & $238(86.5)$ & $25(9.1)$ & $7(2.5)$ & $2(0.7)$ & $3(1.1)$ \\
\hline
\end{tabular}

EDS=exception drug status.

Although it appears that respondents do not necessarily mind the time required to submit an EDS request, they are concerned about their ability to obtain the information necessary for initiating an EDS request. The fact that pharmacists are not likely to have the information required for an EDS request is troubling. The idea behind authorizing pharmacists to apply for EDS on behalf of patients was to increase timely access to prescription drugs for patients. However, when the pharmacist does not have the necessary informa- tion to make that request in a timely manner, the process may actually be lengthened. ${ }^{36}$

An evolving partial solution may be found in the Saskatchewan Pharmaceutical Information Program (PIP). PIP is designed to link community physicians, pharmacies, and hospitals, providing confidential shared access to patient medication histories. ${ }^{46}$ However, while PIP may help alleviate some of the current barriers to pharmacist review of the complete medication history for a patient, it does not provide the pharmacist with access to other medical infor- 
mation, such as the patient diagnosis, that is presently required to initiate an EDS request.

In July 2006, the Saskatchewan Drug Plan implemented 2 changes to help streamline the EDS application process. First, indefinite approval was permitted for 116 drugs or 442 EDS drug information numbers (DINs), analogous to National Drug Code (NDC) numbers in the United States. Second, online adjudication was implemented for 2 drugs, pioglitazone $\mathrm{HCl}$ and rosiglitazone maleate. EDS claims for these agents can be submitted and adjudicated directly through the online claims transactional processing system, which employs a "smart edit" to search for evidence of prior use of first-line therapy or prior use of the target drug that would have been associated with an EDS approval. ${ }^{15}$ While this is a positive step in addressing some of the issues around the administrative workload inherent in PA programs, the online adjudication system currently only includes 2 drugs.

Funding is clearly needed to institute measures that expedite and streamline the manner in which pharmacists apply for EDS, such as the move to online adjudication (smart edit). In addition, consideration must be given to paying pharmacists an appropriate fee for the service they provide. Financial compensation is important because it gives tangible recognition of the pharmacist's professional role in delivering appropriate drug therapy while also providing an incentive for pharmacists and pharmacies to provide a service that clearly benefits patients in improved access to care and physicians in reduced administrative workload.

\section{Limitations}

First, this is a preliminary study of pharmacist perceptions that did not involve collecting information that might be used to improve processes such as the average time required of pharmacy staff per EDS submission and the proportion of total pharmacy time and payroll consumed by the EDS process. Second, the results obtained from the survey pertain only to the province of Saskatchewan, Canada, and may not be applicable to other jurisdictions. Third, since this survey was addressed to community pharmacy managers, the respondents tended to be older and were often the owners of the pharmacies. Therefore, the opinions recorded in this survey may not represent practicing pharmacists in general.

\section{Conclusions}

Pharmacists responding to the survey viewed the EDS program as being beneficial to patients but were concerned with the administrative burden. Concerns with the EDS program focus on the administrative nature of the program, including the inefficient manner in which pharmacists are required to apply for EDS due to lack of access to required patient information, including diagnosis and complete prescription drug history. To maintain pharmacists' support for this managed care intervention, it will be necessary to reduce the administrative workload by providing access to required information and implementing smart edits that scan pharmacy claims history for evidence of prior use of first-line drug therapy. Further research is needed to capture the perceptions and experiences of all stakeholders of the EDS program, including pharmacists, physicians, patients, and drug plan personnel, to help assess humanistic-service outcomes of this managed care intervention.

\section{Authors}

JASON PEREPELKIN, MSc, is a PhD candidate, College of Pharmacy $\&$ Nutrition, Division of Pharmacy, University of Saskatchewan, Canada (this study was completed as part of his master of science program at the University of Saskatchewan); ROY THOMAS DOBSON, $\mathrm{PhD}$, is an associate professor, College of Pharmacy \& Nutrition, Division of Pharmacy, University of Saskatchewan, and served as Perepelkin's supervisor for this study.

AUTHOR CORRESPONDENCE: Jason Perepelkin, MSc, College of Pharmacy \& Nutrition, Division of Pharmacy, University of Saskatchewan, 110 Science Pl., Saskatoon, SK S7N 5C9. Tel: (306) 966-6346; Fax: (306) 966.6377; E-mail: jason.perepelkin@usask.ca

\section{ACKNOWLEDGMENT}

The authors thank Charity Evans, BSP, MSc candidate, College of Pharmacy $\&$ Nutrition, University of Saskatchewan, Canada, for all the time and effort she contributed in reviewing this manuscript and providing invaluable comments and suggestions.

\section{DISCLOSURES}

No outside funding supported this research. The authors disclose no potential bias or conflict of interest relating to this article.

Author Jason Perepelkin served as principal author of the study. Study concept and design were contributed primarily by Perepelkin with input from author Roy Thomas Dobson. Data collection and data interpretation were primarily the work of Perepelkin with input from Dobson. Writing of the manuscript and its revision was primarily the work of Perepelkin with input from Dobson.

\section{REFERENCES}

1. Gross D. Prescription Drug Prices in Canada. Washington, DC: AARP Public Policy Institute; 2003.

2. Anis AH, Guh D, Wang X. A dog's breakfast: prescription drug coverage varies widely across Canada. Med Care. 2001;39(4):315-26.

3. IMS. Pharmaceutical trends. Available at: http://www.imshealthcanada. com. Accessed October 23, 2006.

4. Canadian Institute of Health Information. Drug Expenditure in Canada 1985 to 2005. Ottawa, ON: Author 2006.

5. Rogers Media. Pharmacy Trends Report 2003. Available at: http://www.trendsreport2003.com. Accessed July 29, 2004.

6. Cooksey JA, Knapp KK, Walton SM, Cultice JM. Challenges to the pharmacist profession from escalating pharmaceutical demand. Health Aff. 2002;21(5):182-88.

7. Lewis S, Donaldson C, Mitton C, Currie G. The future of health care in Canada. BMJ. 2001;323:926-29. 
8. Naylor CD. Health care in Canada: incrementalism under fiscal duress. Health Aff. 1999;18(3):9-26.

9. Saskatchewan Health. Drug Plan and Extended Benefits Branch Annual Statistical Report 2005-2006. Regina, SK, Canada: Government of Saskatchewan; 2006

10. Saskatchewan Health. 2007-2008 Saskatchewan Provincial Budget. Regina, SK: Government of Saskatchewan; 2007.

11. Hogerzeil H, Holloway K. How to promote quality use of cost-effective medicines. In: Freemantle N, Hill S, eds. Evaluating Pharmaceuticals for Health Policy and Reimbursement. Malden, MA: Blackwell Publishing Ltd; 2004:174-89.

12. Lexchin J. Effects of restrictive formularies in the ambulatory care setting. Amer J Manag Care. 2002;8(1):69-76.

13. Kielty M. Improving the prior-authorization process to the satisfaction of customers. Amer J Health Syst Pharm. 1999;56:1499-1501.

14. Loh E, Gosnell T, Poston J. Evaluation of Pharmacy Resources Required When Submitting Prescription Claims to Drug Plans. Ottawa, ON, Canada: Canadian Pharmacists Association; 1997.

15. Saskatchewan Health. Formulary —Fifty-Sixth Edition. Available at: http:// formulary.drugplan.health.gov.sk.cal. Accessed April 27, 2007.

16. Saskatchewan Health. Saskatchewan Health Exception Drug Status Request Form. Available at: http://www.forms.gov.sk.ca/he/getformharness. asp? form Name=he602. xft\&preference=PDFFORMS. Accessed June 28, 2007.

17. Larson L, Qualls B, Ward J. COX-II inhibitor prior-authorization process—the untold story (abstract). J Manag Care Pharm. 2001;7(5):366.

18. Cox E, Henderson R, Motheral B. Health plan member experience with point-of-service prescription step therapy. J Manag Care Pharm. 2004;10(4):291-98

19. Dunn J, Cannon H, Mitchell M, Curtiss F. Utilization and drug cost outcomes of a step-therapy edit for generic antidepressants in an HMO in an integrated health system. J Manag Care Pharm. 2006;12(4):294-302.

20. Yokoyama K, Yang W, Preblick R, Frech-Tamas F. Effects of a steptherapy program for angiotensin receptor blockers on antihypertensive medication utilization patterns and cost of drug therapy. J Manag Care Pharm. 2007;13(3):235-44.

21. Dillman DA. Mail and Internet Surveys: The Tailored Design Method. 2nd ed. New York, NY: John Wiley \& Sons Inc.; 2000.

22. Angus DE, Karpetz HM. Pharmaceutical policies in Canada: issues and challenges. Pharmacoecon. 1998;14(suppl 1):81-96.

23. Anis AH. Pharmaceutical policies in Canada: another example of federal-provincial discord. Can. Med. Assoc. 2000;162(4):523-26.

24. Bacovsky RA, Virani R. Prior approval for drug program reimbursementa cross-Canada review. Provin Reimburse Adv. 2004: 37-44.

25. Carroll NV. How effectively do managed care organizations influence prescribing and dispensing decisions? Amer J Manag Care. 2002;8(12):1041-54.

26. Deber RB, Hastings JEF, Thompson GG. Health care in Canada: current trends and issues. J Public Health Policy. 1991;12(1):72-82.

27. Edmunds J, Calnan MW. The reprofessionalisation of community pharmacy? An exploration of attitudes to extended roles for community pharmacists amongst pharmacists and general practitioners in the United Kingdom. Soc Sci Med. 2001;53:943-55.
28. Fullerton DSP, Atherly DS. Formularies, therapeutics, and outcomes: new opportunities. Med Care. 2004;42(suppl 4):III39-III44.

29. Giaquinta D. Session II: Drug formularies—good or evil? A view from a managed care provider. Cardiol. 1994;85(suppl 1):30-35.

30. Grasha AF. Pharmacy workload: the causes and confusion behind dispensing errors. Can Pharm J. 2001;134(3):26-35.

31. Hindmarsh KW. Optimal drug therapy: the role of the pharmacist in bridging the gap between knowledge and action. Can J. Clin Pharmacol. 2001;8(suppl A):53A-54A.

32. Jacobs P, Bachynsky J. Public Policies Related to Drug Formularies in Canada: Economic Issues. Working Paper 00-2. Edmonton, AB, Canada: Institute of Health Economics; 2000.

33. Kozma CM, Reeder CE, Lingle EW. Expanding Medicaid drug formulary coverage: effects on utilization of related services. Med Care. 1990;28(10):963-77.

34. LaPensee KT. Analysis of a prescription drug prior authorization program in a Medicaid health maintenance organization. J Manag Care Pharm. 2003;9(1):36-44.

35. Lexchin J. Effects of restrictive formularies in the ambulatory care setting. Amer J Manag Care. 2001;8(1):69-76.

36. MacKinnon NJ, Kumar R. Prior authorization programs: a critical review of the literature. J Manag Care Pharm. 2001;7(4):297-302.

37. Morgan S. Health Action: Building on the Legacy-Issues for Canadian Pharmaceutical Policy. Ottawa, ON, Canada: The National Forum on Health; 1998.

38. Rosser WW. The place of guidelines and their means of dissemination. Can J Clin Pharmacol. 2001;8(suppl A):34A-38A.

39. Rucker TD, Schiff G. Drug formularies: myths-in-formation. Med Care. 1990;28(10):928-39.

40. Rupp MT, Schondelmeyer SW. Prescribing problems and pharmacist interventions in community practice. Med Care. 1992;30:926-40.

41. Soumerai SB. Benefits and risks of increasing restrictions on access to costly drugs in Medicaid. Health Aff. 2004;23(1):135-46.

42. Soumerai SB, Ross-Degnan D, Fortess EE, Abelson J. A critical analysis of studies of state drug reimbursement policies: research in need of discipline. The Milbank Quarterly. 1993;71(2):217-52.

43. Walser BL, Ross-Degnan D, Soumerai SB. Do open formularies increase access to clinically useful drugs? Health Aff. 1996;15(3):95-109.

44. White AC, Atmar RL, Wilson J, Cate TR, Stager CE, Greenberg SB. Effects of requiring prior authorization for selected antimicrobials: expenditures, susceptibilities, and clinical outcomes. Clin Infect Dis. Accessed 1997;25:230-39

45. Perepelkin J. Pharmacists' experiences with the exception drug status (EDS) program in Saskatchewan [master's thesis]. September 2006. Available at: http://library2.usask.ca/theses/available/etd-09072005-091010/. Accessed October 20, 2000

46. Saskatchewan Health. The Pharmaceutical Information Program. Available at: http://www.health.gov.sk.ca/ph_hisc_proj_pip.html. Accessed July 9, 2005. 